Tropical Journal of Pharmaceutical Research December 2018; 17 (12): 2427-2432

ISSN: 1596-5996 (print); 1596-9827 (electronic)

(1) Pharmacotherapy Group, Faculty of Pharmacy, University of Benin, Benin City, 300001 Nigeria.

Available online at http://www.tjpr.org

Original Research Article

http://dx.doi.org/10.4314/tjpr.v17i12.17

\title{
Effect of Shensong Yangxin on heart failure in preserved ejection fraction rat model
}

\author{
Weiwei Zhang ${ }^{1}$, Qian Sun ${ }^{2 *}$, Hao Chen $^{3}$, Qiang Zhang ${ }^{1}$ \\ ${ }^{1}$ Department of Cardiovascular Medicine, ${ }^{2}$ Department of Pharmacy, Dezhou People's Hospital, 3Department of Internal \\ Medicine, The People's Hospital of Qingyun County, Dezhou, China
}

*For correspondence: Email: Zhangqiangljhyi@163.com

Sent for review: 12 September 2018

Revised accepted: 28 November 2018

\begin{abstract}
Purpose: To investigate the interventional effect of ShensongYangxin (SSYX) on heart failure (HF) using preserved ejection fraction (HFpEF) rat model.

Methods: HFpEF rat model was established using abdominal aorta coarctation method and randomly divided into a positive drug control group; SSYX at high, medium, and low dosage groups; and normal control group. After 8 weeks oral treatment of SSYX, echocardiography and cardiac catheterization were used to investigate the effects of SSYX on HFpEF rat cardiac functions, including mean heart rate $(H R)$, left ventricle anterior and posterior wall thicknesses at end diastole (LVAWd + LVPWd), left ventricular internal diameter at end diastole (LVIDd), and left ventricle mass (LVM).

Results: SSYX markedly decreased heart weight and improved survival rate $(p<0.01)$ after 12 weeks of treatment. The expression of NT-proBNP decreased in a dose-dependent manner and was significantly lower in SSYX treatment groups $(p<0.01)$. Compared with normal control group, expression of CaMK II, PKA and RyR2 was significantly lower $(p<0.005)$, while expression level of SERCA2a significantly increased after $4 \mathrm{~g} / \mathrm{kg} /$ day SSYX treatment $(p<0.01)$.

Conclusion: SSYX significantly attenuates HFPEF-induced cardiac dysfunction and increases survival rate, suggesting that SSYX may prevent HF via regulation of cytoplasmic $\mathrm{Ca}^{2+}$ handling. SSYX reduces plasma NT-proBNP levels, lending support for its therapeutic potential in HF management.
\end{abstract}

Keywords: Heart failure, Ejection fraction, Shensong Yangxin

This is an Open Access article that uses a funding model which does not charge readers or their institutions for access and distributed under the terms of the Creative Commons Attribution License (http://creativecommons.org/licenses/by/4.0) and the Budapest Open Access Initiative (http://www.budapestopenaccessinitiative.org/read), which permit unrestricted use, distribution, and reproduction in any medium, provided the original work is properly credited.

Tropical Journal of Pharmaceutical Research is indexed by Science Citation Index (SciSearch), Scopus, International Pharmaceutical Abstract, Chemical Abstracts, Embase, Index Copernicus, EBSCO, African Index Medicus, JournalSeek, Journal Citation Reports/Science Edition, Directory of Open Access Journals (DOAJ), African Journal Online, Bioline International, Open-J-Gate and Pharmacy Abstracts

\section{INTRODUCTION}

Heart failure with preserved ejection fraction (HFpEF) is predominantly found in older adults with hypertension, diabetes mellitus, and atrial fibrillation [1,2]. HFpEF causes various cardiovascular complications related to diastolic left ventricular (LV) dysfunction [3]. HFpEF accounts for $50 \%$ of HF cases, and its prevalence is rising at an alarming rate of $1 \%$ per year [4].. In contrast to HFrEF, some studies on neurohumoral suppression in HFpEF failed to reach a positive outcome [6]. The diagnosis of $\mathrm{HFpEF}$ involves typical symptoms of HF such as the LV ejection fraction (LVEF) LVEF > 50, left ventricular end-diastolic volume index (LVEDVI) $<97 \mathrm{ml} / \mathrm{m}^{2}$, left ventricular end-diastolic pressure $($ LVEDP) $>16 \mathrm{mmHg}$ or pulmonary artery wedge 
pressure $(\mathrm{PCWP})>12 \mathrm{mmHg}$, and Doppler mitral flow spectrum:peak diastolic velocity/early diastolic velocity $\left(E / E^{\prime}\right)>15$. When the value of $E / E^{\prime}$ is between 8 and 15 , other non-invasive evidence of LV diastolic dysfunctions such as peak $E$ deceleration time or pulmonary venous flow spectrum analyses is necessary [7].

The alteration of cardiac structure has been associated with aberrant expression of calmodulin-dependent protein kinase II (CaMK II), sarcoplasmic reticulum cata-ATPase (SERCA2a), protein kinase A (PKA), phospholamban (PLB), and ryanodine receptor 2 (RyR2 receptor) [8]. In normal cardiomyocytes, phosphorylation of phosphoproteins during diastolic phase and dissociation from SERCA2a enhances the affinity between SERCA2a and $\mathrm{Ca}^{2+}$ [9]. When phosphorylated PLB binds SERCA2a, the affinity of SERCA2a for $\mathrm{Ca}^{2+}$ is decreased [10].

Brain natriuretic peptide (BNP) is a cardiovascular peptide hormone, mainly secreted by the ventricle, which can sensitively reflect LV functional changes [11]. When the cardiac volume load or pressure load increases, BNP is synthesized in the heart and secreted into the bloodstream, which increases the plasma levels of BNP[12].

The traditional Chinese medicine, Shensong Yangxin capsules (SSYX), has been used effectively to treat cardiovascular disease. The bioactive components of SSYX include sodium danshensu (sodium 3-(3,4dihydroxyphenyl)-2-hydroxypropanoate),

chlorogenic acid, and gensenoside Rb1 [13]. However, the effects of SSYX on HFpEF remains unclear. The aim of this study was therefore to investigate the intervening effect of SensongYangxi in the HFpEF rat model to provide pharmacological evidence for its clinical application in HFpEF.

\section{EXPERIMENTAL}

\section{Establishment of HFpEF animal model and treatments}

Healthy Sprague-Dawley male rats weighing 180-240 g were purchased from Changzhou Experimental Animal Co. (China). This animal study was approved by the ethics committee of Dezhou People's Hospital (approval no. 20180521), and the guidelines for the use of experimental animals of the National Institutes of Health were followed [14]. The animals were kept under standard laboratory conditions (temperature: $22{ }^{\circ} \mathrm{C} ; 12 \mathrm{~h} / 12 \mathrm{~h}$ day-night cycle) and divided randomly into seven groups (each group, $\mathrm{n}=8$ ): normal control, positive control (HFpEF rats), HFpEF rat $+4 \mathrm{~g} / \mathrm{kg}$ SSYX, HFpEF rat $+0.8 \mathrm{~g} / \mathrm{kg}$ SSYX, HFpEF rat $+0.2 \mathrm{~g} / \mathrm{kg}$ SSYX, f) HFpEF rat $+0.5 \mathrm{~g} / \mathrm{kg}$ metoprolol, and $\mathrm{HFpEF}$ rat + $0.5 \mathrm{~g} / \mathrm{kg}$ metoprolol+ $0.8 \mathrm{~g} / \mathrm{kg}$ SSYX. HFpEF rats were established as described previously [15].

Following standard methodology [16], the rats were fixed in a supine position after intraperitoneal anesthesia (20\% uratan injection of $5 \mathrm{~mL} / \mathrm{kg}$ ). The abdominal aorta was separated using a longitudinal incision on the median line of abdomen, and was ligated. In the sham operation group, the abdominal aorta and left renal artery were separated and threaded but not ligated. Penicillin (200,000 U/day for 3 days, intramuscular injection) was used to prevent infection, and the rats were fed with standard diet.

\section{Reagents and preparation of SSYX}

ShensongYangxin (SSYX), purchased from Shijiazhuang Yiling Pharmaceutical (Shijiazhuang, China), was resuspended in double-distilled water and was used to treat the rats. The SSYX was prepared daily. The herbal drug was authenticated and standardized based on marker compounds according to the Chinese Pharmacopoeia (National Pharmacopoeia Committee, 2005).

\section{Assessment of cardiac function}

All groups of animals were anesthetized by intraperitoneal injection with $5 \%$ sodium pentobarbital sodium $(45 \mathrm{mg} / \mathrm{kg})$. Thereafter the hair was removed and the rats were placed on a thermostatic heater in a supine position. The mean heart rate $(H R)$, left ventricle anterior and posterior wall thicknesses at end diastole (LVAWd+LVPWd), left ventricular internal diameter at end diastole (LVIDd), left ventricle mass (LVM), left ventricular ejection fraction (EF $\%$ ), and left ventricular short-axis contraction rate were measured using echocardiography (Visual Sonics, Toronto, Canada). The mean values of the measurements were calculated.

\section{Western blot analysis}

Heart tissues $(30 \mu \mathrm{g})$ were homogenized in lysis buffer and protein concentration was assessed using the bicinchoninic acid (BCA) assay (Thermo Fisher Scientific, Waltham, MA, USA). The protein samples were then resolved using 10 $\%$ SDS polyacrylamide gels and transferred to Immobilon-P transfer membranes and incubated in blocking solution (4\% non-fat milk). The 
membranes were probed overnight with a 1:2,000 dilution of primary antibodies to: CaMK II (Abcam, Cambridge, MA, USA), PKA (Santa Cruz Biotechnology, Santa Cruz, CA, USA), RyR2 (Abcam), and SERCA2a (Abcam). Glyceraldehyde 3-phosphate dehydrogenase (Abcam) was used as an internal control. The blotted proteins were detected using a chemiluminescent system.

\section{Statistical analysis}

Data are presented as mean \pm standard deviation (SD). The comparison between multiple groups was performed using one-way analysis of variance (ANOVA). Statistical significance was set at $p<0.05$. SPSS software for Windows, version 17.0 (SPSS, Chicago, IL, USA) was used for statistical analysis.

\section{RESULTS}

\section{Effect of SSYX on survival rates and cardiac weight of HFpEF rats}

To evaluate the effect of SSYX on HF, HFpEF rats were used to establish the $\mathrm{HR}$ model. The rat diastolic LV function was significantly increased, and the cardiovascular reserve function was impaired, indicating successful establishment of the HFpEF model. The survival rate after 12 weeks of treatment was analyzed, which showed a dose-dependent increase and the 12-week survival rate was significantly higher in the SSYX $4 \mathrm{~g} / \mathrm{kg} /$ day group than in the model group (Figure 1A).

In addition, compared with the SSYX $4 \mathrm{~g} / \mathrm{kg} / \mathrm{day}$ group, the survival rate was significantly increased in the $0.5 \mathrm{~g} / \mathrm{kg} /$ day metoprolol +0.8 $\mathrm{g} / \mathrm{kg} / \mathrm{d}$ SSYX group. Moreover, Figure 1B shows that the heart weights were significantly decreased in a dose-dependent manner with SSYX treatment. The heart weight in the 0.5 $\mathrm{g} / \mathrm{kg} /$ day metoprolol + $0.8 \mathrm{~g} / \mathrm{kg} / \mathrm{d}$ SSYX group was found to be lower than that of the $4 \mathrm{~g} / \mathrm{kg} /$ day SSYX or $0.5 \mathrm{~g} / \mathrm{kg} /$ day metoprolol groups. These results suggest that SSYX may confer protective effect against $\mathrm{HF}$, and the combination of metoprolol and SSYX exerts synergic protective effects against HF.

\section{Effect of SSYX on cardiac function in HFpEF rats}

To determine whether SSYX regulates cardiac functions in HF, the mean HR, LVAWd + LVPWd, LVIDd, LVM, EF \%, and FS \% were assessed using echocardiographic parameters. The data for different groups of HFpEF rats are summarized in Table 1. Compared with the sham group, the HR, LVAWd + LVPWd, LVIDd, and LVM were significantly increased in the model group, which were accompanied by lower EF \% and FS \%. SSYX treatment induced a significant decrease in HR, LVAWd + LVPWd, LVIDd, and LVM, which were associated with increased EF\% and FS\%. Furthermore, treatment with $0.5 \mathrm{~g} / \mathrm{kg} / \mathrm{d}$ metoprolol + $0.8 \mathrm{~g} / \mathrm{kg} / \mathrm{d}$ SSYX reversed the effects induced by HF. These results indicate that SSYX is able to regulate cardiac function during HF.
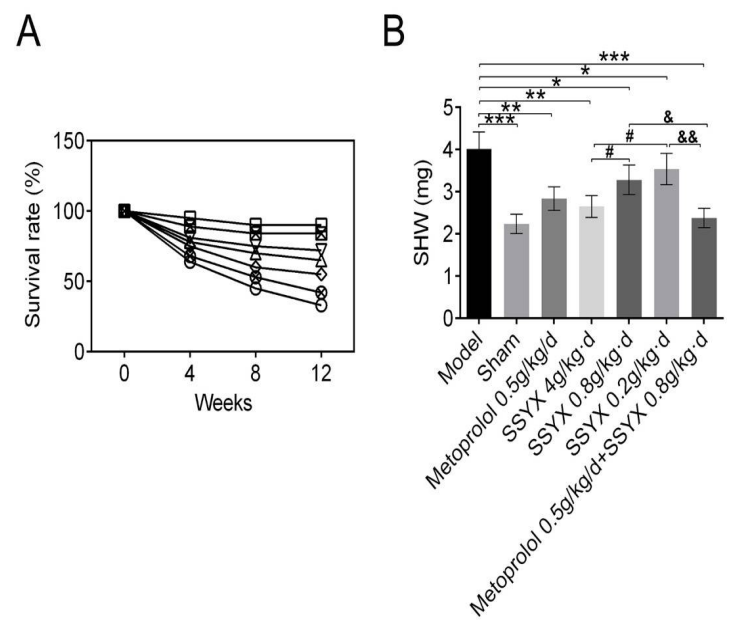

Figure 1: Cardioprotective effects of SSYX on survival rate and cardiac weight in HFpEF rats. (A) The survival rate in different treatment groups. $₫$ : 0.5 $\mathrm{g} / \mathrm{kg} /$ day metoprolol $+0.8 \mathrm{~g} / \mathrm{kg} /$ day SSYX; 0.2 $\mathrm{g} / \mathrm{kg} /$ day $\mathrm{SSYX} ; \diamond: 0.8 \mathrm{~g} / \mathrm{kg} /$ day $\mathrm{SSYX} ; \quad: 4.0$ $\mathrm{g} / \mathrm{kg} /$ day SSYX; $\triangle: 0.5 \mathrm{~g} / \mathrm{kg} /$ day metoprolol; $\square$ : sham; $\circ$ : model; (B) The cardiac weight in different treatment groups. Data are presented as mean $\pm S D$, using Student's $t$-test; " compared with the model; " compared with $4 \mathrm{~g} / \mathrm{kg} / \mathrm{d}$ SSYX, and compared with $0.5 \mathrm{~g} / \mathrm{kg} / \mathrm{d}$ metoprolol + $0.8 \mathrm{~g} / \mathrm{kg} / \mathrm{d}$ SSYX $\left({ }^{*} p<0.05,{ }^{* *} p<0.01,{ }^{* *} p\right.$ $<0.005,{ }^{\#} p<0.05,{ }^{\&} p<0.05$, and $\left.{ }^{\& \&} p<0.01\right)$

\section{SSYX inhibits NT-proBNP expression in HFpEF rats}

$\mathrm{N}$-terminal brain natriuretic peptide (NT-proBNP) and BNP are peptide hormones released predominantly by ventricular myocytes. The specific NT-proBNP detection assay is therefore useful for the diagnosis of HF. As shown in Table 2, plasma NT-proBNP levels in the model group were significantly higher than that of the sham group. The expression of NT-proBNP decreased in a dose-dependent manner and was significantly lower in the $4 \mathrm{~g} / \mathrm{kg} / \mathrm{d}$ SSYX group than in the model group. Similarly, NT-proBNP levels decreased significantly in the $0.5 \mathrm{~g} / \mathrm{kg} / \mathrm{d}$ metoprolol $+0.8 \mathrm{~g} / \mathrm{kg} /$ day SSYX groups. 
Table 1: Effect of SSYX on echocardiographic parameters

\begin{tabular}{|c|c|c|c|c|c|c|}
\hline Group & $\begin{array}{l}\text { HR } \\
\text { (bmp) }\end{array}$ & EF\% & FS\% & $\begin{array}{l}\text { LVAWd+LV } \\
\text { PWd (mm) }\end{array}$ & LVIDd (mm) & LVM (mg) \\
\hline Control & $335 \pm 21$ & $50.14 \pm 5.06$ & $21.69 \pm 2.74$ & $4.32 \pm 0.41$ & $55.69 \pm 5.68$ & $1185.18 \pm 106.17$ \\
\hline Sham & $304 \pm 27^{\star *}$ & $68.70 \pm 7.24^{\star *}$ & $40.58 \pm 4.01^{* *}$ & $3.21 \pm 0.31^{*}$ & $27.74 \pm 2.14^{\star *}$ & $820.63 \pm 125.64^{\star *}$ \\
\hline $\begin{array}{l}\text { Metoprolol }(0.5 \\
\mathrm{g} / \mathrm{kg} / \mathrm{d})\end{array}$ & $327 \pm 22^{*}$ & $62.45 \pm 6.55^{\star}$ & $30.54 \pm 3.01 *$ & $3.66 \pm 0.35^{*}$ & $38.12 \pm 3.55^{\star}$ & $1039 \pm 130.15^{*}$ \\
\hline $\begin{array}{l}\text { SSYX (4 } \\
\mathrm{g} / \mathrm{kg} / \mathrm{d})\end{array}$ & $310 \pm 20 *$ & $64.50 \pm 6.85^{\star}$ & $32.55 \pm 3.21^{*}$ & $3.56 \pm 0.34^{*}$ & $33.66 \pm 4.21^{*}$ & $852 \pm 163.89^{*}$ \\
\hline $\begin{array}{l}\operatorname{SSYX}(0.8 \\
\mathrm{g} / \mathrm{kg} / \mathrm{d})\end{array}$ & $325 \pm 23^{*}$ & $60.12 \pm 6.38 * \# \&$ & $\begin{array}{l}28.36 \pm 3.01^{*} \# \\
\&\end{array}$ & $3.71 \pm 0.36^{*} \&$ & $39.26 \pm 3.02^{*} \&$ & $\begin{array}{l}1055 \pm 189.26 * \& \\
\&\end{array}$ \\
\hline $\begin{array}{l}\operatorname{SSYX}(0.2 \\
\mathrm{g} / \mathrm{kg} / \mathrm{d})\end{array}$ & $330 \pm 10$ & $57.33 \pm 6.34^{*} \# \& \&$ & $\begin{array}{l}26.44 \pm 2.78^{*} \# \\
\&\end{array}$ & $4.02 \pm 0.40 \# \&$ & $\begin{array}{l}43.55 \pm 4.31^{*} \# \\
\&\end{array}$ & $1100 \pm 169.29^{*} \# \&$ \\
\hline $\begin{array}{l}\text { Metoprolol }(0.5 \\
\text { g/kg/d) + SSYX }\end{array}$ & $308 \pm 20^{* *}$ & $64.25 \pm 6.15^{\star *}$ & $38.54 \pm 3.56^{\star *}$ & $3.35 \pm 0.33^{*}$ & $31.67 \pm 5.61^{* *}$ & $830.45 \pm 100.25^{\text {** }}$ \\
\hline
\end{tabular}
$(0.8 \mathrm{~g} / \mathrm{kg} / \mathrm{d})$

Compared with control group, ${ }^{\#}$ compared with $4 \mathrm{~g} / \mathrm{kg} / \mathrm{d}$ SSYX group, ${ }^{\&}$ compared with $0.5 \mathrm{~g} / \mathrm{kg} / \mathrm{d}$ metoprolol +0.8 $\mathrm{g} / \mathrm{kg} / \mathrm{d}$ SSYX group $\left({ }^{*} p<0.05,{ }^{* *} p<0.01,{ }^{\#} p<0.05,{ }^{\&} p<0.05\right.$, and $\left.{ }^{\& \&} p<0.01\right)$

Table 2: Effect of SSYX on NT-proBNP plasma levels

\begin{tabular}{ll}
\hline Group & NT-proBNP $/ \mathrm{ng} \mathrm{L}^{-1}$ \\
\hline Control & $303.45 \pm 10.26$ \\
Sham & $185.46 \pm 18.49^{\star *}$ \\
Metoprolol $(0.5 \mathrm{~g} / \mathrm{kg} / \mathrm{d})$ & $256.39 \pm 14.58^{*}$ \\
SSYX $(4 \mathrm{~g} / \mathrm{kg} / \mathrm{d})$ & $229.35 \pm 13.92^{*}$ \\
SSYX $(0.8 \mathrm{~g} / \mathrm{kg} / \mathrm{d})$ & $250.26 \pm 15.18^{\star} \# \&$ \\
SSYX $(0.2 \mathrm{~g} / \mathrm{kg} / \mathrm{d})$ & $286.89 \pm 20.34 \# \&$ \\
Metoprolol $(0.5 \mathrm{~g} / \mathrm{kg} / \mathrm{d}+$ & \\
SSYX 0.8 g/kg/d) & \\
\hline
\end{tabular}

Compared with the control group, " compared with 4 $\mathrm{g} / \mathrm{kg} / \mathrm{d}$ SSYX, ${ }^{\text {\& }}$ compared with $0.5 \mathrm{~g} / \mathrm{kg} / \mathrm{d}$ metoprolol + $0.8 \mathrm{~g} / \mathrm{kg} / \mathrm{d}$ SSYX group $\left({ }^{\star} p<0.05,{ }^{* *} p<0.01,{ }^{\#} p<0.05\right.$, $\left.{ }^{2} p<0.05\right)$

\section{Effect of SSYX on $\mathrm{Ca}^{2+} /$ calmodulin-dependent protein expression in HFpEF rats}

To determine whether CaMK II, PKA, RyR2, and SERCA2a are involved in the regulation of $\mathrm{HF}$, the expression of these proteins was detected by western blotting. As shown in Figure 2, compared with the model group, the expression levels of CaMK II, PKA, and RyR2 were significantly decreased (Figure $2 \mathrm{~A}, \mathrm{~B}$ and Figure $3 \mathrm{~A}$ ). Furthermore, the expression level of SERCA2a was significantly increased after $4 \mathrm{~g} / \mathrm{kg} / \mathrm{day}$ SSYX treatment (Figure3 B). In accordance with the SSYX treatment, the $0.5 \mathrm{~g} / \mathrm{kg} /$ day metoprolol + $0.8 \mathrm{~g} / \mathrm{kg} /$ day SSYX treatment group also increased CaMK II, PKA, and RyR2 expression and enhanced the expressions of SERCA2a. These data provide further evidence that SSYX may be able to prevent HF.

\section{DISCUSSION}

Heart failure is a major public health problem in the world, and continues to increase in prevalence at an alarming rate [17]. This study first determined whether SSYX could prevent HF. The results showed that SSYX had a protective effect on HFpEF, and that the combination of metoprolol and SSYX exerted a synergic protective effect on HF. These findings are consistent with previous results which showed that SSYX effectively improved the arrhythmic in the heart [18].
A

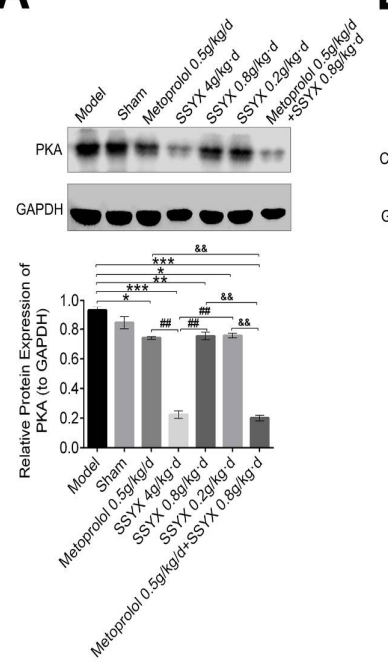

B

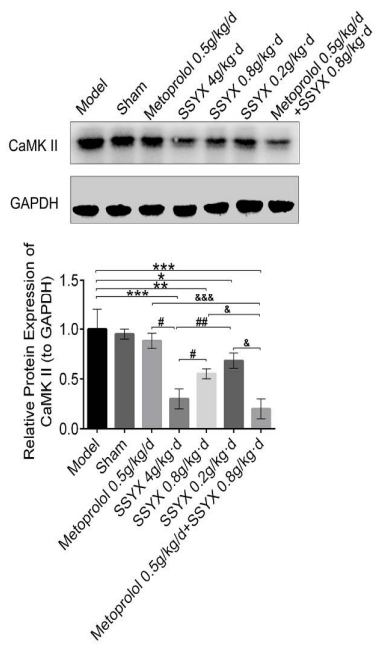

Figure 2: Effect of SSYX on CaMK II and PKA expression in HFpEF rats. (A, B) Western blot data show suppression of PKA and CaMK II after treatment with SSYX and metoprolol. Statistical analysis was performed according to the Material and Methods. Data are presented as the mean \pm SD, using Student's $t$-test, "Compared with the model group, \# compared with the $4 \mathrm{~g} / \mathrm{kg} / \mathrm{d}$ SSYX group, and compared with the $0.5 \mathrm{~g} / \mathrm{kg} / \mathrm{d}$ metoprolol $+0.8 \mathrm{~g} / \mathrm{kg} / \mathrm{d}$ SSYX group ( ${ }^{*} p<$ $0.05, \quad p<0.01, \quad p<0.005,{ }^{*} p<0.05,{ }^{*} p<0.05$, and $\left.{ }^{\& \&} p<0.01\right)$

Trop J Pharm Res, December 2018; 17(12): 2430 
A
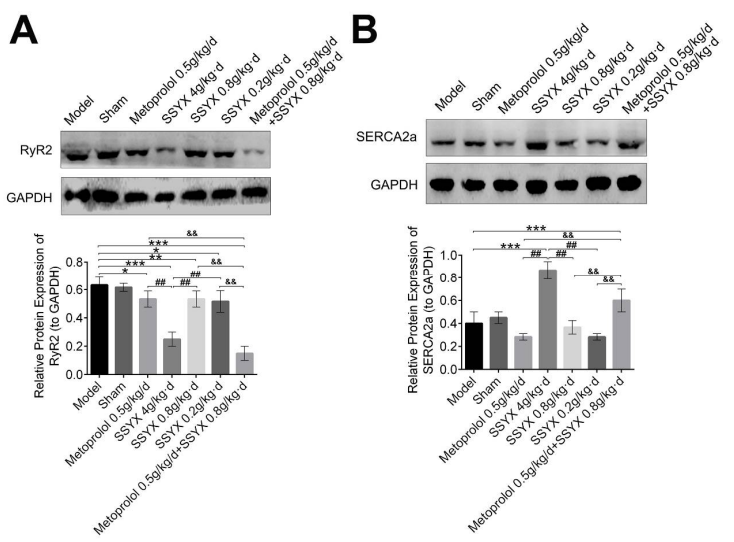

Figure 3: Effect of SSYX on RyR2 and SERCA2a expression in HFpEF rats. (A) Western blots show suppression of RyR2 levels after treatment with SSYX and metoprolol. (B) Western blots show increased SERCA2a expression after SSYX and metoprolol treatment. Statistical analysis was performed according to the Material and Methods. Data are reported as the mean $\pm S D$, using Student's $t$-test, "Compared with the model group, " compared with the $4 \mathrm{~g} / \mathrm{kg} / \mathrm{d}$ SSYX group, and compared with the 0.5 $\mathrm{g} / \mathrm{kg} / \mathrm{d}$ metoprolol $+0.8 \mathrm{~g} / \mathrm{kg} / \mathrm{d}$ SSYX group ( ${ }^{*} p<0.05$, $p<0.01, \quad p<0.005,{ }^{\#} p<0.05,{ }^{\&} p<0.05$, and ${ }^{\& \&} p<$ $0.01)$

To evaluate the effects of SSYX on cardiac function, the mean HR, LVAWd + LVPWd, LVIDd, and LVM were assessed using echocardiography. Subsequently, the heart weight in different treatment groups was also investigated. Treatment with SSYX reversed the effects induced by HF and decreased the heart weight, which was increased by HFpEF. Furthermore, the expression of NT-proBNP was decreased with SSYX treatment. The results showed that SSYX might be able to regulate cardiac function during HF in human patients. CaMK II is involved in some key aspects of acute cellular $\mathrm{Ca}^{2+}$ handling related to cardiac function [19]. CaMKII activity changes in the myocardium during HF, enhances the activity of RyR2, and promotes the release of $\mathrm{Ca}^{2+}$ from the sarcoplasmic reticulum $[9,20]$.

These results therefore determined whether the effect of $\mathrm{Ca}^{2+}$-mediated cellular responses could assist the diagnosis of cardiac hypertrophy and HF. In the present study, when SSYX was used to treat different groups of HFpEF rats, the expression levels of CaMKII, PKA, and RyR2 were significantly decreased and SERCA2a was significantly increased. These results are consistent with previous studies showing that the $\mathrm{Ca}^{2+}$-ATPase mRNA levels for SERCA2a were decreased in LV failure and that SSYX was able to prevent $\mathrm{HF}$ by regulating cytoplasmic $\mathrm{Ca}^{2+}$ levels[21].

\section{CONCLUSION}

These findings show that SSYX significantly attenuates HFpEF-induced cardiac dysfunction and thus increases survival rate in rats. SSYX prevents $\mathrm{HF}$ by regulating cytoplasmic $\mathrm{Ca}^{2+}$ handling and inhibiting the expression of NTproBNP. Therefore, these results provide a possible new therapeutic strategy for the treatment of HFpEF.

\section{DECLARATIONS}

\section{Conflict of Interest}

No conflict of interest associated with this work.

\section{Contribution of Authors}

We declare that this work was done by the authors named in this article and all liabilities pertaining to claims relating to the content of this article will be borne by the authors. Weiwei Zhang and Qian Sun designed all the experiments and revised the paper. HaoChen performed the experiments, Qiang Zhang as corresponding author wrote the paper and approved the final version of the manuscript.

\section{REFERENCES}

1. Rietbrock S, Heeley E, Plumb J, van Staa T. Chronic atrial fibrillation: Incidence, prevalence, and prediction of stroke using the Congestive heart failure, Hypertension, Age> 75, Diabetes mellitus, and prior Stroke or transient ischemic attack (CHADS2) risk stratification scheme. American heart journal. 2008; 156(1): 57-64.

2. Movahed M-R, Hashemzadeh M, Jamal MM. Diabetes mellitus is a strong, independent risk for atrial fibrillation and flutter in addition to other cardiovascular disease. International journal of cardiology. 2005; 105(3): 315318.

3. Grossman W. Diastolic dysfunction in congestive heart failure. New England Journal of Medicine. 1991; 325(22): 1557-1564.

4. Savarese G, Lund LH. Global public health burden of heart failure. Cardiac failure review. 2017; 3(1): 7-13.

5. Upadhya B, Taffet GE, Cheng CP, Kitzman DW. Heart failure with preserved ejection fraction in the elderly: scope of the problem. Journal of molecular and cellular cardiology. 2015; 83: 73-87.

6. Shah SJ, Kitzman DW, Borlaug BA, Van Heerebeek L, Zile MR, Kass DA, Paulus WJ. Phenotype-specific treatment of heart failure with preserved ejection fraction: a multiorgan roadmap. Circulation. 2016; 134(1): 73-90.

7. Paulus WJ, Tschöpe C, Sanderson JE, Rusconi C, Flachskampf FA, Rademakers FE, Marino $P$, Smiseth

Trop J Pharm Res, December 2018; 17(12): 2431 
OA, De Keulenaer G, Leite-Moreira AF. How to diagnose diastolic heart failure: a consensus statement on the diagnosis of heart failure with normal left ventricular ejection fraction by the Heart Failure and Echocardiography Associations of the European Society of Cardiology. European heart journal. 2007; 28(20): 2539-2550.

8. Terentyev $D$, Belevych AE, Terentyeva R, Martin MM, Malana GE, Kuhn DE, Abdellatif M, Feldman DS, Elton TS, Gyorke S. miR-1 overexpression enhances Ca2+ release and promotes cardiac arrhythmogenesis by targeting PP2A regulatory subunit B56a and causing CaMKIl-dependent hyperphosphorylation of RyR2. Circulation research. 2009; 104(4): 514-521.

9. Ai X, Curran JW, Shannon TR, Bers DM, Pogwizd SM. Ca2+/calmodulin-dependent protein kinase modulates cardiac ryanodine receptor phosphorylation and sarcoplasmic reticulum Ca2+ leak in heart failure. Circulation research. 2005; 97(12): 1314-1322.

10. MacLennan DH, Kranias EG. Calcium: phospholamban: a crucial regulator of cardiac contractility. Nature reviews Molecular cell biology. 2003; 4(7): 566-574.

11. Troughton RW, Frampton CM, Yandle TG, Espine EA, Nicholls MG, Richards AM. Treatment of heart failure guided by plasma aminoterminal brain natriuretic peptide (N-BNP) concentrations. The Lancet. 2000; 355(9210): 1126-1130.

12. Dispenzieri $A$, Kyle $R$, Lacy $M$, Jaffe $A$, Therneau $T$, Zeldenrust S, Gertz M. Serum cardiac troponins and Nterminal pro-brain natriuretic peptide: a staging system for primary systemic amyloidosis. Amyloid and Amyloidosis. 2004: 67-77.

13. Jiang $X$, Jia J, Li Y. Simultaneous determination of eight bioactive constituents in shensong yangxin capsule by UPLC. Chinese Herbal Medicines. 2013; 5(3): 212-216.
14. Olfert $E D$, Mcwilliam $A A$, Olfert $E D$, Mcwilliam $A A$. GUIDE TO THE CARE AND USE OF EXPERIMENTAL ANIMALS. Canadian Veterinary Journal. 1980; 26(1): 49-58.

15. Dobrev D, Wehrens XH. Role of RyR2 phosphorylation in heart failure and arrhythmias: Controversies around ryanodine receptor phosphorylation in cardiac disease. Circulation research. 2014; 114(8): 1311-1319.

16. Paulus WJ, van Ballegoij JJ. Treatment of heart failure with normal ejection fraction: an inconvenient truth! Journal of the American College of Cardiology. 2010; 55(6): 526-537.

17. Bonow RO, Smaha LA, Smith Jr SC, Mensah GA, Lenfant C. World Heart Day 2002: the international burden of cardiovascular disease: responding to the emerging global epidemic. Circulation. 2002; 106(13): 1602-1605.

18. Li N, Ma K-j, Wu X-f, Sun Q, Zhang Y-h, Pu J-I. Effects of Chinese herbs on multiple ion channels in isolated ventricular myocytes. CHINESE MEDICAL JOURNALBEIJING-ENGLISH EDITION-. 2007; 120(12): 10681078.

19. Berridge MJ, Bootman MD, Roderick HL. Calcium: calcium signalling: dynamics, homeostasis and remodelling. Nature reviews Molecular cell biology. 2003; 4(7): 517-524.

20. Wehrens $X H$, Lehnart SE, Reiken SR, Marks AR. Ca2+/calmodulin-dependent protein kinase II phosphorylation regulates the cardiac ryanodine receptor. Circulation research. 2004; 94(6): e61-e70.

21. Lokuta AJ, Maertz NA, Meethal SV, Potter KT, Kamp TJ, Valdivia $H H$, Haworth $R A$. Increased nitration of sarcoplasmic reticulum Ca2+-ATPase in human heart failure. Circulation. 2005; 111(8): 988-995. 